\title{
A Novel Catalytic Reactor System for Transient Response and Its Use in $\mathrm{CO}$ Oxidation on $\mathrm{Pd} / \mathrm{Al}_{2} \mathrm{O}_{3}$
}

\author{
Yoav Barshad and Frdogan Gulari ${ }^{1}$ \\ Department of Chemical Engineering, University of Michigan, Ann Arbor, Michigan 48109
}

Received September 17, 1984; revised March 20, 1985

\begin{abstract}
In this paper we describe a computer-controlled reactor system capable of imposing any concentration-forcing function on the input. Combination of a monolithic support with a fast-scan Fourier Transform Infrared (FTIR) results in a system capable of detecting all the IR-active species inside the reactor simultaneously, with a time resolution of $0.17 \mathrm{~s}$. Flow characteristics and typical results obtained from oxidation of $\mathrm{CO}$ over $\gamma$-alumina-supported palladium demonstrate the capabilities of this reactor system in detecting fast phenomena that could not be observed by analysis of the effluent stream. $\mathcal{O} 1985$ Academic Press. Inc.
\end{abstract}

\section{INTRODUCTION}

The main body of literature aimed at unveiling the path by which heterogeneous catalytic reactions proceed is based on steady-state experiments. In 1943 Hougen and Watson ( $I$ ) introduced a technique by which rate expressions could be obtained from elementary steps by invoking a ratelimiting step assumption. It then became a common practice to postulate a number of "plausible" mechanisms, derive a rate expression for each one using the rate-limiting step approach and use rate data from a large number of steady-state experiments to find the "right" one by the goodness of fit between the experimental data and the rate expression. Unfortunately, this process may result in differences in goodness of fit that are well within the experimental error or give the same result for totally different models. In other words, it is not discriminating enough in most cases. Weller (2) has shown how misleading this method can be by analyzing the rate data of Akers and White (3). He showed that a single parameter model fits the data just as well as the original complex rate expression based on an elementary step mechanism.

${ }^{1}$ To whom correspondence should be addressed.
Furthermore, a steady-statc ratc cquation such as the Langmuir-Hinshelwood mentioned above assumes that the rate of each step is a linear function of any other step, and that there is no appreciable accumulation of surface intermediates at any point. Using such rate expressions to predict the dynamic behavior of a reactor (especially when the transient and the reaction have comparable characteristic times), or self-sustained oscillations (4) will result in serious errors.

Apart from the early work of Wagner and Hauffe (5) who used the transient method to elucidate the mechanism by which water is formed over palladium by measuring the electrical conductivity, and the introduction of the pulse method as a microcatalytic technique by Kokes et al. (6), it was only in the early 1960's that the transient method was extensively applied to heterogeneous catalysis. It was realized by a number of researchers that, compared to steady-state data, dynamic or transient studies will usually furnish much additional information. This is due to the fact that transient response will tend to reflect the nature of individual steps while the steady state is the combined response.

Methods to monitor adsorption during the course of reaction were proposed by 
Tamaru (7). He realized that dynamic methods combined with modern analytical techniques will be the right tools for acquiring data on surface intermediates and their reactivity. A dynamic method where the inlet concentration into the reactor is perturbed was initially proposed by Bennett (8). He suggested that rate constants of individual steps can be calculated using this method.

Kobayashi and Kobayashi (9) have reviewed the principles of transient response experiments explaining how the response curves can be interpreted. The implementation of this method, using a tubular reactor for oxidation of $\mathrm{CO}$ on various metal oxides and decomposition of nitrous oxide on $\mathrm{MnO}_{2}$, is presented.

Bennett $(10)$ reviewed some of the past work in both the transient method and periodic operation of catalytic reactors. In this paper Bennett discusses the details of mathematical modeling for dynamic studies, the requirements from catalytic reactors suitable for dynamic studies, and how the transient data can be interpreted. $\mathrm{He}$ also chose the decomposition of $\mathrm{N}_{2} \mathrm{O}$ as an example of how the proposed method can be applied. Some of the more recent efforts in this area by Kobayashi (11) are to formulate a general method of interpretation of the response curves. A similar attempt was presented by Schadlich et al. (12).

A typical transient experiment consists of forcing a well-defined concentration change on the inlet stream and monitoring the outlet stream concentrations for the response to that change. The underlying assumption is that the gas-phase concentration reflects the dynamic behavior of the surface processes of interest, or that gas-phase concentration responds rather quickly to changes in the inlet stream (forcing function). This requires optimizing the ratio of surface species to gas-phase species in the reactor. The variety of reactors that can be and were used is described elsewhere $(13,14)$, but we would like to use the coarse division of "one pass"' and gradient- less reactors for purposes of the following discussion.

Gradientless reactors are mathematically very simple and can be described by a set of ordinary differential equations. The major disadvantage to using gradientless reactors in transient response experiments is their filtering action which makes it impossible to impose or detect sharp concentration transients. A second disadvantage is the need for high-pressure operation ( $>250 \mathrm{psi}$ ) for internally recycled gradientless reactors.

Our studies of forced-concentration cycling of catalytic reactors required a reactor which allowed the imposition of very sharp concentration gradients at a fairly high frequency and detection of the gas-phase transients in the immediate vicinity of the catalyst with high time resolution. The wall-catalyzed monolithic reactor satisfied both of these requirements. The honeycomb support was chosen because its parallel straight channels allowed a view line through the reactor thus with an FTIR spectrophotometer the gas phase in the immediate vicinity of the catalyst surface can be continuously monitored with high signalto-noise ratio.

The wall-catalyzed reactor has no merit in ease of mathematical treatment but presents a well-defined problem in the sense that the flow is a fully developed laminar flow with the reaction occurring only at the boundaries. This allows for welldefined mass and heat transfer studies to and from the surface. We were also surprised that although efforts to model the monolithic support mathematically were carried out $(15,16)$, the use of this attractive support was mainly restricted to emission control studies, and there is a paucity of experimental data for other systems.

Catalytic $\mathrm{CO}$ oxidation on palladium is almost an ideal system to evaluate the performance of this reactor system. The catalyst is very stable at low temperatures $(<200 \mathrm{C})$, both $\mathrm{CO}$ and $\mathrm{CO}_{2}$ can be detected by IR quantitatively even at low concentrations and the reaction kinetics is fast. In 
addition there is ample literature data (17, 18), most notably high-vacuum work by Engel and co-workers on single crystals of palladium.

It is commonly agreed upon that the reaction proceeds through the following steps on palladium:

$$
\begin{aligned}
\mathrm{CO} & \rightleftarrows \mathrm{CO}_{\text {ads }} \\
\mathrm{O}_{2} & \rightleftarrows 2 \mathrm{O}_{\text {ads }} \\
\mathrm{CO}_{\text {ads }}+\mathrm{O}_{\text {ads }} & \rightarrow \mathrm{CO}_{2}
\end{aligned}
$$

no evidence for the existence of the ER mechanism has been found (17).

It has been shown, however, that the rate cannot be written as a product of a bimolecular rate constant and the coverage of the two adsorbed species (17).

\section{DETAILS OF THE REACTOR SYSTEM}

A general schematic of the flow system and the data acquisition system can be seen in Fig. 1. A detailed description of the components and operation is given below.

Data acquisition and control. The heart of the information management part of the reactor system is a HP9836A desktop computer (dashed lines in Fig. 1). The computer serves as an active controller on an IEEE488 interface bus. The interface between the computer and the various control and measurement elements is done through the HP9842A multiprogrammer. The multiprogrammer performs a variety of high-speed switching tasks through a matrix switch card. The output of the various transducers is digitized by a fast (HP-69751A) A/D card in the multiprogrammer. A reading and updating cycle consisting of 10 individual measuring points can be repeated four times a second. Data acquisition, control, display of the results on the screen, and data storage for further processing are all done in real time.

Inlet manifold. To impose a variety of concentration forcing functions on the reactor's inlet, the following setup was used. Three solenoid valves (ITT S301) located on each of the inlet streams were used to impose step or square wave functions. In

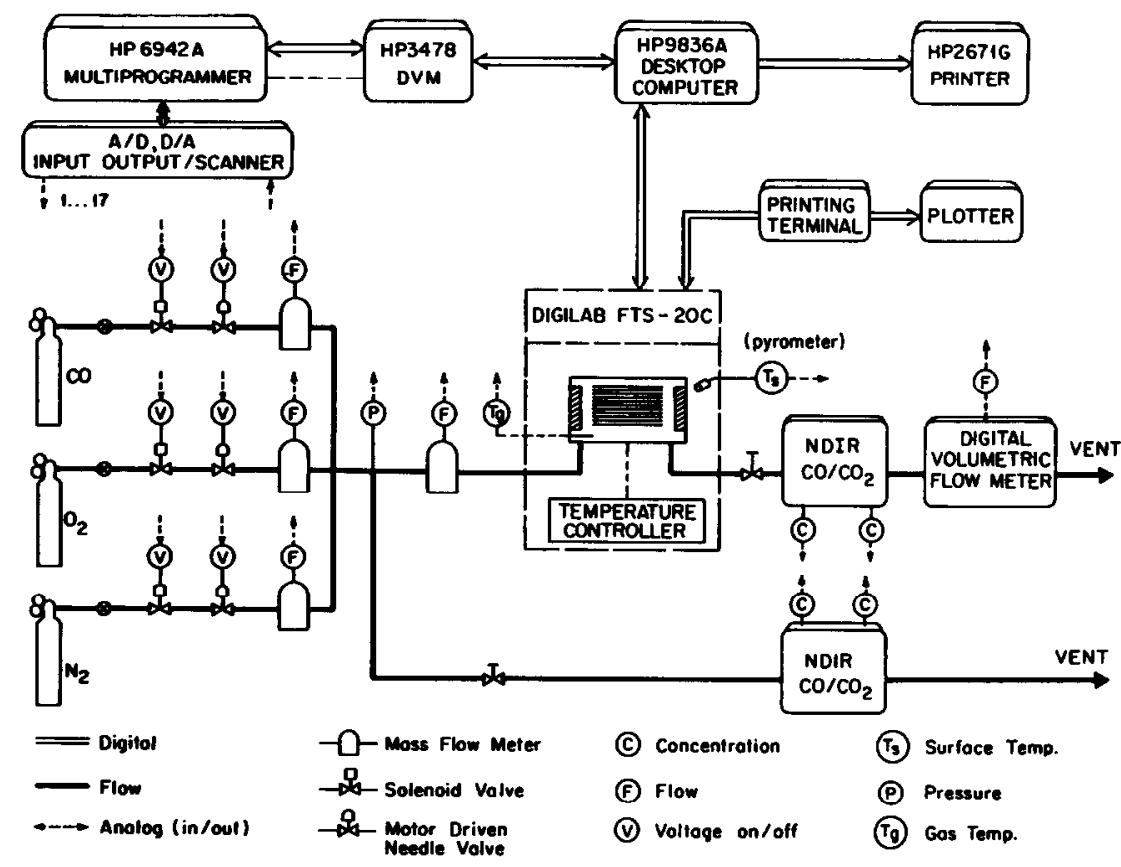

FIG. 1. Schematic of the setup. Tubes are represented by solid lines, analog data by dashed lines, and digital data by double solid lines. 
the data presented here only $\mathrm{CO}$ and $\mathrm{O}_{2}$ were switched on and off. In this case, the needle valves following these solenoids were used to set a steady-state flow in such a way that, when one of the reactants was switched off, $\mathrm{N}_{2}$ was taking its place and the gas-phase concentration of the other reactant was unchanged. We found this arrangement to be quite successful, giving space velocities consistent to within $3 \%$ in most cases.

The control loop of each of the needle valves consists of a fast-response ( $25 \mathrm{~ms}$ to 95\% of final reading) mass flow meter (Kurz NE505) which is monitored four times a second by the HP9836. A proportional controller with built-in dead time and varying proportionality "constant" is used by the computer to drive a micrometer-metering valve (Whitey SS-22RS4) by a miniature dc motor. This control loop can be used for either setting a steady-state value for square wave functions or for any preprogrammed functions (periodic or not).

The reactor. The body of the reactor is a 80-mm long, 38-mm o.d., and 32-mm i.d. tube machined from 304 stainless steel (see Fig. 2). To make sure that the changes in the concentration of the inlet reaches all channels at the same time, a flow distributor, preheater is installed at the entrance section. The flow distributor consists of a circular channel with 10 radial holes. The feed is introduced into the catalyst bed

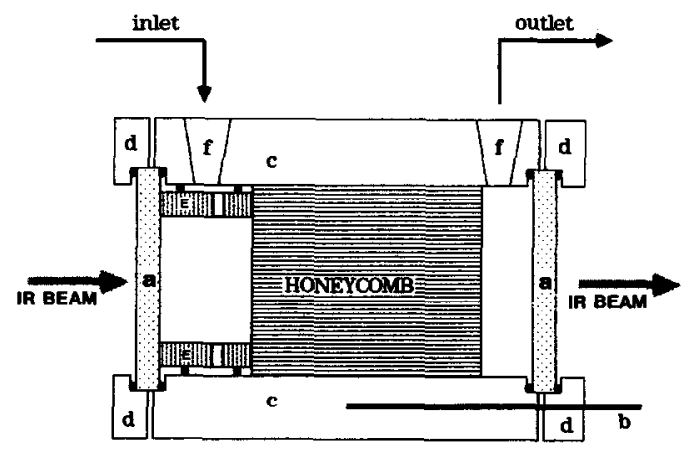

FIg. 2. Details of the reactor. (a) $\mathrm{NaCl}$ windows, (b) thermocouple, (c) reactor body, (d) flanges, (e) flow distribution, (f) inlet/outlet. (O) O-Rings. through the radial holes. Two $\mathrm{NaCl}$, or other suitable windows, are installed on both ends sealed with Parker fret-12 0rings. The O-rings can withstand temperatures up to $240^{\circ} \mathrm{C}$; for higher temperatures, Graphoil or another type of gasket material can be used. With this configuration the inlet mixing cup occupies $18 \%$ of the total volume, the catalyst bed $71 \%$, and the outlet mixing cup $11 \%$. Viewing angle through the monolith channels is $\Delta \theta=2.1^{\circ}$. Since IR detection depends on the path length, special care was taken to maximize the contribution by the monolith to the path length. In terms of the percentage of the total path length, the outlet mixing volume contributes $\simeq 3 \%$, the catalyst channels $80 \%$, the inlet mixing volume $17 \%$. With this arrangement, contribution of the reactor to the product spectra is $\approx 96 \%$ and to the reactant spectra is $80 \%$.

The two $\mathrm{NaCl}$ windows at both ends permit monitoring of the thermal radiation from the catalyst surface. The windows have negligible emissivities, compared with the dark catalyst surface, and are transparent to thermal radiation in the range of 4 to $14 \mu \mathrm{m}\left(0\right.$ to $\left.250^{\circ} \mathrm{C}\right)$. As indicated in Fig. 1 , a pyrometer (Omega OS-600) is aimed at the catalyst surface to measure the catalyst surface temperature.

Catalyst. A cylindrical piece, $34 \mathrm{~mm}$ long and $32 \mathrm{~mm}$ in diameter, was core-drilled from an Engelhard monolith. A wash coat of alumina (20\% wt) was applied and calcined. The metal was impregnated by successively dipping and drying to obtain $1 \%$ wt palladium on the surface. The physical properties can be seen in Table 1 .

In our studies of $\mathrm{CO}$ oxidation the Reynolds number in the catalyst channels ranged from 1 to 2 , corresponding to flow rates of 500 and $1000 \mathrm{~cm}^{3 /} / \mathrm{min}$. Based on studies by Boersma et al. (19) and Vrentas et al. (20) 94 to $96 \%$ of the total length of the reactor is in the fully developed flow regime. For $500 \mathrm{~cm}^{3} / \mathrm{min}$ the average linear velocity is $2.4 \mathrm{~m} / \mathrm{min}$ which gives an average residence time of $2 \mathrm{~s}$. 
TABLE 1

Physical Properties of the Catalyst

\begin{tabular}{lc}
\hline Channel dimension (reclangular) & $1.2 \mathrm{~mm}$ \\
Channel density & $50.5 \mathrm{Ch} . / \mathrm{cm}^{2}$ \\
Wall thickness & $0.3 \mathrm{~mm}$ \\
Open area & $64.0 \%$ \\
Geometric area & $24.5 \mathrm{~cm}^{2} \mathrm{~cm}^{-3}$ \\
Apparent density & $0.8 \mathrm{~g} \mathrm{~cm}^{-3}$ \\
BET surface area (apparent) & $15.3 \mathrm{~m} \mathrm{~m}^{2} / \mathrm{g}$ \\
Dispersion & $21.0 \%$ \\
\hline
\end{tabular}

Detection system. Currently the reactor system has two independent IR detection systems. The feed and product stream concentrations are monitored by two IR industries (IR No. 7100) nondispersive infrared analyzers. Each detector is capable of following two frequency ranges simultaneously. Switching between pairs of gases of interest is relatively simple and requires replacing the detector/filter assembly.

Our second (and main in this case) detection system is a Digilab FTS-20C FTIR. The collimated IR beam of the FTIR goes through the honeycomb structure of the monolithic support, providing true detection inside the reactor. This results in axial averaging of the concentration along the length of the laminar-flow, wall-catalyzed reactor.

Thanks to an array processor, the FTIR can perform data acquisition under two different modes, one slightly easier to use with extensive real time data analysis and screen support (GCS mode), and a faster kinetic mode requiring postacquisition data analysis. Most of the data presented here were acquired under GCS with time resolution of $0.5 \mathrm{~s}$ that was found to be adequate for this study. This program takes two complete spectra per second (each consisting of four to six individual scans) and integrates up to five wavenumber regions which are displayed and stored in real time. Simultaneously, complete $8-\mathrm{cm}^{-1}$ resolution spectra are stored on disk and can be reanalyzed for any number of regions after data acquisition. In this study only two regions were explored: 2253 to $2423 \mathrm{~cm}^{-1}$ for $\mathrm{CO}_{2}$ and 1998 to $2253 \mathrm{~cm}^{-1}$ for CO. Note that, qualitatively, time resolution is limited to a single scan, while the numbers stated above are for scan sets consisting of four to five individual scans. In the faster kinetic mode, individual single scan interferograms are acquired at the rate of six per second. The resolution can be as high as $2 \mathrm{~cm}^{1}$ at this speed. After the data acquisition is completed, the interferograms are converted into absorbance spectra and the regions of interest are digitally integrated to give the concentrations of all the components.

\section{EXPERIMENTAL PERFORMANCE}

Flow and transport characteristics. The monolithic support is an attractive flow system for heterogeneous catalytic reactions, in terms of heat and mass transfer between the catalytic wall and the flowing gas. According to Wei (21), assuming infinitely fast kinetics, the conversion for a monolith is given by

$$
\text { Conversion }=1-\exp \left(-\frac{S h \cdot A \cdot L}{R e \cdot S c}\right) .
$$

The Sherwood number $S h$, which may be assumed to be equal to the Nusselt number, was found (22) to be a mildly increasing function of the Reynolds number, falling between the asymptotic values for constant wall temperature and constant wall flux. The Reynolds number can vary (under our conditions) between 1 and 2 , since the Schmidt number is close to one. Equation (2) shows that under these conditions an infinitely fast reaction will indeed give complete conversion as the exponential term goes to zero $(A \cdot L$ has a value of 180$)$.

Analysis of heat transfer for laminar flow in a closed conduit is a classical problem (23). Analytical solutions are available for a variety of boundary and initial conditions (24). Correlations for calculating an average Nusselt number, such as the SeiderTate correlation, yield very good approxi- 
mations. Under the flow conditions of this study, a typical Nusselt number is 4.6. Giving a heat transfer coefficient of $0.02 \mathrm{~W} /$ $\mathrm{cm}^{2} \cdot{ }^{\circ} \mathrm{C}$, which should not result in any significant $\left(\geq 1^{\circ} \mathrm{C}\right)$ temperature difference between the gas phase and the wall.

Taylor and Aris (25) have solved the complete convective diffusion equation for the case of laminar flow in round tubes. According to their results for relatively low Reynolds numbers dispersion is governed by molecular diffusion and the Taylor diffusion coefficient $D_{\mathrm{T}}$ is equal to $D_{\mathrm{AB}}$ (the molecular diffusion coefficient). Under these conditions the concentration profile will not follow the parabolic velocity profile but will be close to plug flow. The variance of an incoming pulse as it travels down a channel is given by

$$
\sigma^{2}=\frac{2 \cdot D_{\mathrm{T}} \cdot L}{U}
$$

For the experimental conditions of this study $\left(500 \mathrm{~cm}^{3} / \mathrm{min}\right) \sigma^{2}$ is equal to a $0.4 \mathrm{~cm}^{2}$.

Identification of the residence time distribution (RTD) was carried out by sending a rectangular $\mathrm{CO}$ pulse into the reactor and monitoring both the outlet and the average reactor concentration for different flow rates. Fig. 3 shows the average response to pulse functions at 500 and $1000 \mathrm{~cm}^{3} / \mathrm{min}$. In

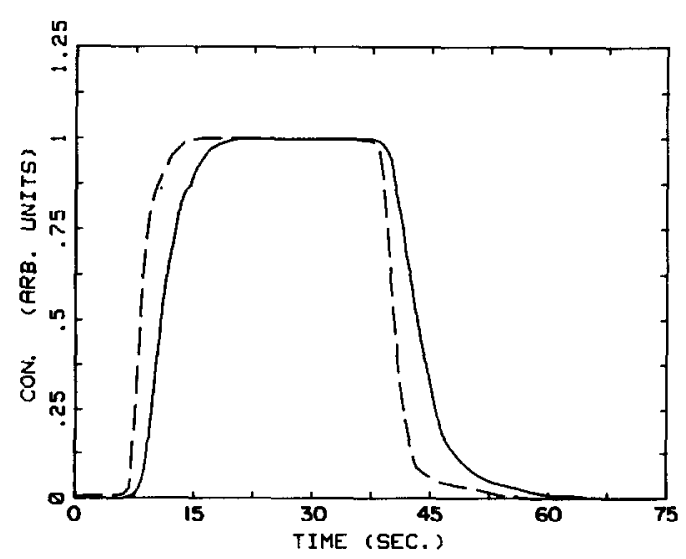

FIG. 3. Axial average concentration response to a 30-s CO pulse at flow rates 500 (dashed lines) and 1000 (solid line) $\mathrm{cm}^{3} / \mathrm{min}$. both cases the pulse was of the same length (30 s) and was begun at the same point. The lag time between the solenoid valves and the reactor's inlet can be measured directly from this figure. Since the reactor consists of an entrance mixing cup, laminar flow monolith, and an exit mixing cup, we can see some exponential behavior at the two ends, connected with a straight line that is due to the front propagation through the monolith. Analysis of the response curves gives a slope (as percentage of final value) of $23 \% / \mathrm{s}$ for the flow rate $500 \mathrm{~cm}^{3} / \mathrm{min}$ and $40 \% / \mathrm{s}$ for $1000 \mathrm{~cm}^{3} / \mathrm{min}$.

With the monolithic support the absorbance measured by the spectrophotometer is an axial average of the concentration inside the reactor and no spatial discrimination can be performed. The axial averaging prevents time resolution of periodic phenomena faster than half the residence time. In cases where a single transient is monitored this is not a problem since a qualitative reading can be obtained superimposed on the background signal.

\section{RESULTS AND DISCUSSION}

To demonstrate the advantages of the see through reactor we have used it in studying transient response and periodic operation for the oxidation of $\mathrm{CO}$ over supported palladium. The experimental work presented here was carried out at $100^{\circ} \mathrm{C}$ and at atmospheric pressure. The feed was switched between $10 \% \mathrm{CO}$ in $\mathrm{N}_{2}$ and $10 \% \mathrm{O}_{2}$ in $\mathrm{N}_{2}$. The main objective was to compare the axial average concentration in the reactor, as a function of time, with the analysis of the effluent stream. However, the results have implications for understanding the mechanism under atmospheric pressure, by extending high-vacuum work (17).

Figure 4 presents the $\mathrm{CO}$ and $\mathrm{CO}_{2}$ responses to switching the feed from $\mathrm{N}_{2}$ to $10 \% \mathrm{CO}$ in $\mathrm{N}_{2}$, where the catalyst was pretreated with $\mathrm{O}_{2}$ for a long period of time. Figure $4 \mathrm{~b}$ is the integrated absorbance at 2253 to $2423 \mathrm{~cm}^{-1}$ for $\mathrm{CO}_{2}$ and 2000 to 2250 $\mathrm{cm}^{-1}$ for $\mathrm{CO}$. While Fig. $4 \mathrm{a}$ is the axial av- 

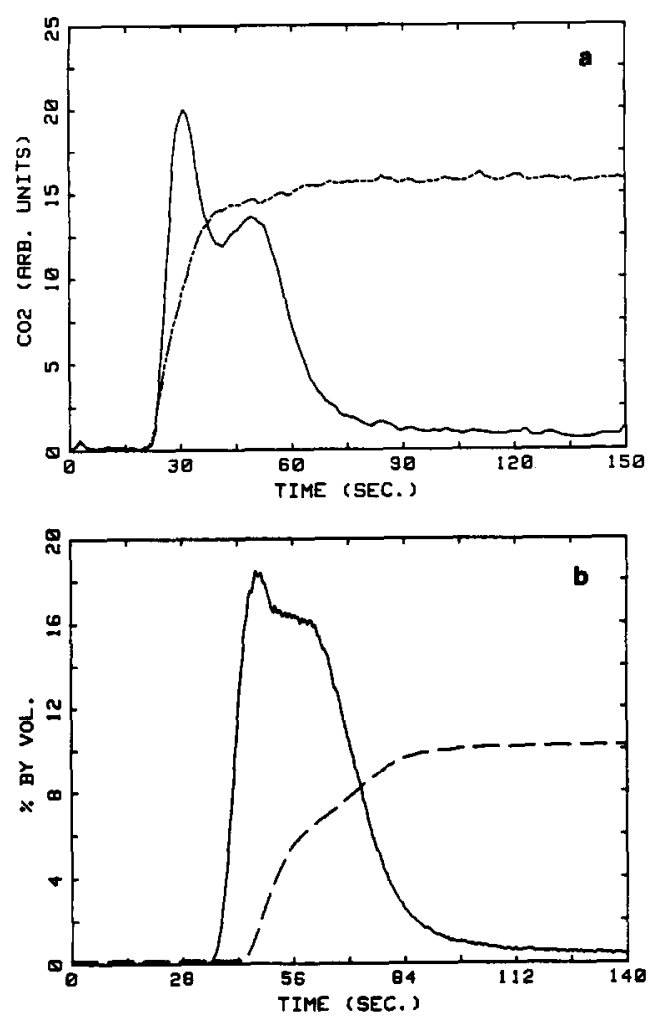

Fig. 4, $\mathrm{CO}$ and $\mathrm{CO}_{2}$ transient response for a feed switch from $\mathrm{N}_{2}$ to $10 \% \mathrm{CO}$ in $\mathrm{N}_{2}$. Catalyst was pretreated with $\mathrm{O}_{2}$. (a) The result with the see-through reactor. (b) The response from the external detector. $\mathrm{CO}_{2}$, solid line; $\mathrm{CO}$, dashed line.

erage concentration as a function of time, Fig. $4 \mathrm{~b}$ is the response of the effluent IR analyzer with a relatively small $(\tau=2 \mathrm{~s})$ residence time.

The two major differences between Figs. $4 a$ and $b$ are that while we see two clear maxima in a, we see only one maximum in $b$, with a distinct shoulder indicating that the two peaks seen in $b$ have merged into one. In Fig. 4a the rise of $\mathrm{CO}$ and the $\mathrm{CO}_{2}$ production begin at the same point, but at the outlet we see that $\mathrm{CO}$ rises $10 \mathrm{~s}$ after $\mathrm{CO}_{2}$. We see that although we can observe $\mathrm{CO}$ in the gas phase inside the reactor, it is being adsorbed and reacted on the surface and cannot break out of the reactor to be detected by the effluent IR analyzer.

Figure 5 shows the opposite experiment. The catalyst was pretreated with $\mathrm{CO}$ and the gas phase was purged with $\mathrm{N}_{2}$ before switching the feed to $10 \% \mathrm{O}_{2}$ in $\mathrm{N}_{2}$. The see-through reactor results shown in Fig. 5a provide information that cannot be obtained by external detection. Some of the surface $\mathrm{CO}$ gets displaced into the gas phase, before $\mathrm{CO}_{2}$ production starts! even though the length of the $\mathrm{CO}$ transient seen is somewhat longer than the residence time, no $\mathrm{CO}$ is detected with the more sensitive external detector. This indicates that all the displaced $\mathrm{CO}$ readsorb and react without leaving the reactor. Comparing this transient to the one presented in Fig. 4 we see a much faster rise of the $\mathrm{CO}_{2}$ transient. The time to reach the half height being determined by the residence time of the reactor. While the overall shape of the transient is similar to the one given in Fig. 4 a the peak-
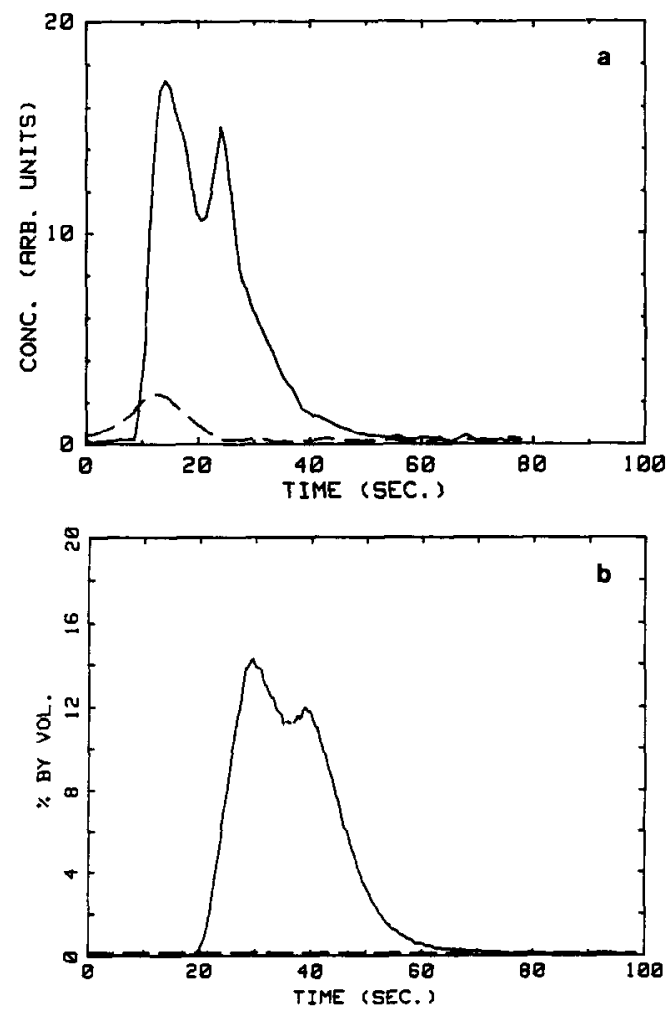

FIG. 5. $\mathrm{CO}$ and $\mathrm{CO}_{2}$ transient response for a feed switch from $\mathrm{N}_{2}$ to $10 \% \mathrm{O}_{2}$ in $\mathrm{N}_{2}$. Catalyst was pretreated with $\mathrm{CO}$. (a) The result with the see-through reactor. (b) The response from the external detector $\mathrm{CO}_{2}$, solid line; $\mathrm{CO}$, dashed line. 
to-peak time is 11 versus $17 \mathrm{~s}$. The integrated amount of $\mathrm{CO}_{2}$ produced is $2 \times 10^{-4}$ mol indicating that the same number of sites are occupied by both $\mathrm{CO}$ and oxygen. The dispersion value can be found by assuming one oxygen atom per palladium atom and one $\mathrm{CO}$ atom bridging two palladium atoms. The result is that $4.01 \times 10^{-4}$ mol of palladium is exposed, which are $21.3 \%$ of the $0.2 \mathrm{~g}$ of palladium that was loaded on the substrate.

Experiments that were conducted at lower temperatures revealed an interesting behavior that is somewhat related to this phenomena. Adsorbed $\mathrm{CO}$ did not react immediately when exposed to oxygen, resulting in a lag time which is a strong function of temperature. The desorption of $\mathrm{CO}$ is an activated process which explains the temperature dependency of the time lag. Before any oxygen can adsorb and react, some $\mathrm{CO}$ has to desorb and vacate some active sites. We also found that this corresponded very well to the minimum time period needed to achieve rate enhancement under periodic operation (26).

A second set of experiments is presented in Figs. 6 and 7. The feed was switched from $10 \% \mathrm{O}_{2}$ in $\mathrm{N}_{2}$ to $10 \% \mathrm{O}_{2}$ and $10 \% \mathrm{CO}$ in $\mathrm{N}_{2}$. This results in a $\mathrm{CO}_{2}$ production profile that is almost identical with the one for an oxygen-pretreated catalyst, but the amount of $\mathrm{CO}_{2}$ that was produced in this case (where the integration was carried out to the same point as in Fig. 4) was lessonly $3.3 \times 10^{-4} \mathrm{~mol}$, or $81 \%$ of the amount produced by pretreating with oxygen. In this case, oxygen is maintaining a certain surface coverage and the constant $\mathrm{O}_{2}$ partial pressure regenerates those sites. When the feed is switched back to $10 \% \mathrm{O}_{2}$ in $\mathrm{N}_{2}$ (see Fig. 7) there is a surge of $\mathrm{CO}_{2}$ with a distinct shoulder. In both cases there is quite a difference between the axial average response, Figs. $6 b$ and $7 b$, and the effluent response in Figs. 6a and 7a.

The opposite experiment, where $\mathrm{O}_{2}$ is switched on and off into a constant partial pressure of $\mathrm{CO}$, did not show any interest- ing behavior and resulted in a slow and steady increase to steady state with a characteristic time of about $30 \mathrm{~s}$.

The clear separation of the double peaks observed in the $\mathrm{CO}_{2}$ transients and observation of desorbed $\mathrm{CO}$, which readsorbed without leaving the reactor show the superiority of inside-the-reactor detection in comparison to external detection.

The double-peaked structure of the $\mathrm{CO}_{2}$ transients is probably a result of different surface $\mathrm{CO}$ species. As $\mathrm{CO}$ is introduced into the reactor, the surface is saturated with oxygen. The small initial concentration of $\mathrm{CO}$ results in reaction between rapidly diffusing $\mathrm{CO}$ molecules and stationary oxygen islands (17). In this regime the reaction is rapid and the rate is independent of oxygen coverage. As the surface coverage
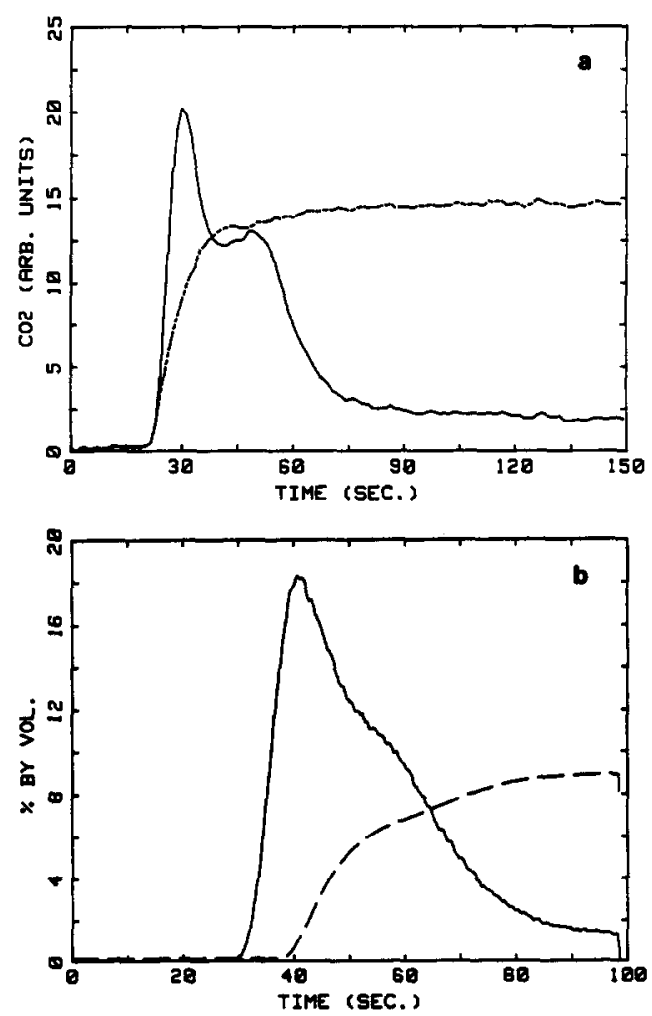

FIg. 6. $\mathrm{CO}$ and $\mathrm{CO}_{2}$ transient response for a feed switch from $10 \% \mathrm{O}_{2}$ in $\mathrm{N}_{2}$ to $10 \% \mathrm{O}_{2}$ and $10 \% \mathrm{CO}$ in $\mathrm{N}_{2}$. (a) The result with the see-through reactor. (b) The response from the external detector. $\mathrm{CO}_{2}$, solid line; $\mathrm{CO}$, dashed line. 

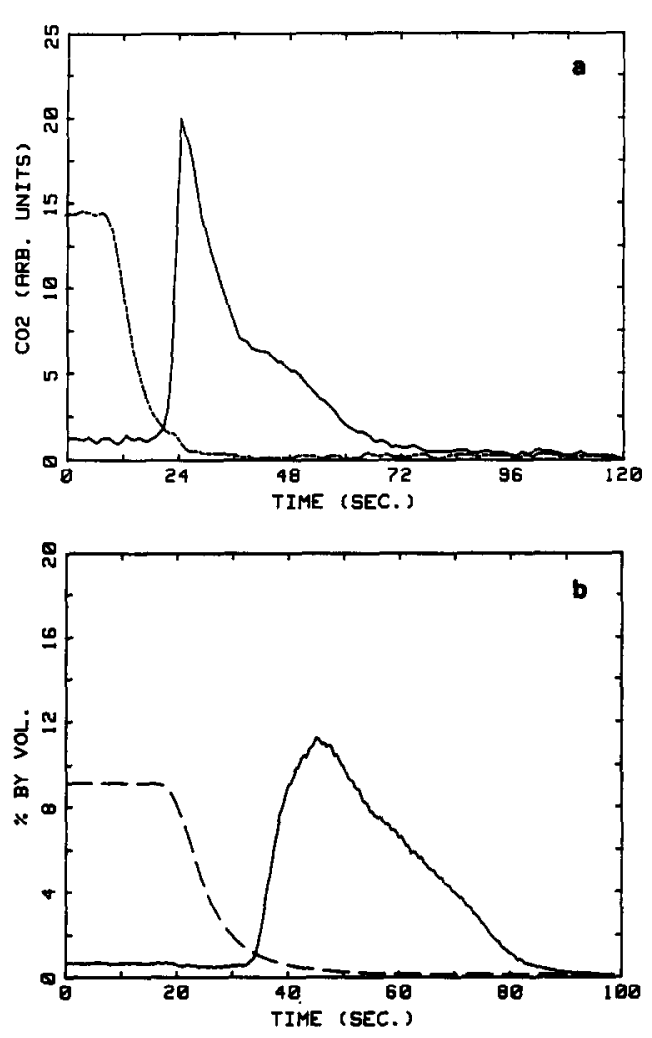

FIG. 7, $\mathrm{CO}$ and $\mathrm{CO}_{2}$ transient response for a feed switch from $10 \% \mathrm{CO}$ and $10 \% \mathrm{O}_{2}$ in $\mathrm{N}_{2}$ to $10 \% \mathrm{O}_{2}$ in $\mathrm{N}_{2}$. (a) The result with the see-through reactor. (b) The response from the external detector. $\mathrm{CO}_{2}$, solid line; $\mathrm{CO}$, dashed line.

of $\mathrm{CO}$ increases, islands of a mixed surface structure containing both $\mathrm{CO}$ and oxygen (17) may be formed, which results in an increased rate of reaction giving rise to the second peak. While this explanation works for the oxygen-covered catalyst, it does not explain the reasons for the double peak observed with a CO-covered catalyst. A second possibility for the presence of two peaks may also be different reactivities of adsorbed $\mathrm{CO}$ and oxygen on 100 and 111 (the thermodynamically most stable $\mathrm{Pd}$ planes) planes of the catalyst.

A third explanation that has been suggested is that the second peak is a result of a thermal shock, created by the initial reaction rate, and traveling right behind the reaction front. This possibility can be ruled out based on a number of calculations and observations.

a. Similar experiments with platinum did not show any double-peak transients for oxygen-pretreated catalyst though all the experimental conditions and the heat of reaction are the same.

b. A pyrometer (Omega OS-600) located (measuring the catalyst temperature from IR emission) at the outside did not detect any temperature excursions on the catalyst surface and neither did the gas-phase thermocouple.

c. Calculations based on the heat diffusivity (27) of the substrate indicate that serious temperature excursions are not possible if all the substrate is taken into account $\left(>2^{\circ} \mathrm{C}\right)$.

We have also observed that the presence of the second peak is a strong function of the catalyst temperature and exposure time to $\mathrm{CO}$. Increasing the temperature decreases the time between the two peaks, finally merging into one. Also exposure to $\mathrm{CO}$ or $\mathrm{O}_{2}$ for very short times eliminates the second peak. These are additional evidences against thermal shock argument.

Further support of the true kinetic nature of the observed overshoots is that a similar overshoot for the same system was observed in a UHV work (17) with partial pressure of $\mathrm{CO}$ equal to $3 \times 10^{-3}$ Torr. Under such conditions it is impossible to have any temperature excursions, but we can still see the overshoot in the rate of $\mathrm{CO}_{2}$ production.

\section{CONCLUSIONS}

The use of a monolithic support in combination with the FTIR to monitor the gasphase concentration inside the reactor is a powerful and useful technique. Although the data are not easily interpreted (mathematically), monitoring the fast transients in the gas phase before any mixing occurs gives insight into phenomena not observable before. This reactor can also be used for steady-state studies as well to obtain axial average concentration. 
The use of this reactor to study $\mathrm{CO}$ oxidation on $\mathrm{Pd} / \mathrm{Al}_{2} \mathrm{O}_{3}$ shows the value of a through-the-reactor detection system for transient response studies. The most important one is the observation that $\mathrm{CO}$ desorbs upon the introduction of oxygen into a CO-pretreated reactor resulting in a temperature-dependent lag time. This $\mathrm{CO}$ could not be detected outside the reactor. Furthermore, analysis of the effluent stream at high temperature suggests that $\mathrm{CO}_{2}$ production leads the gas-phase $\mathrm{CO}$. Through the reactor detection shows that both rise simultaneously with a slight lead of the CO. We can conclude by saying that the oxidation proceeds through surface reaction between adsorbed $\mathrm{CO}$ and atomic oxygen the rate of which is a complex function of the surface coverage by both reactants. Our results also show in a clear manner the reason for a minimum time period needed under periodic operation to achieve rate enhancement. This is the desorption time of $\mathrm{CO}$ to allow adsorption of $\mathrm{O}_{2}$. The desorption is a crucial step for a high initial rate of reaction when switching between the two reactants.

\section{APPENDIX: NOMENCLATURE}

\section{Roman}

A geometric area

$C$ concentration

$D_{\mathrm{AB}}$ diffusion coefficient

$D F$ duty fraction

$D_{\mathrm{T}}$ Taylor diffusion coefficient

$L$ length

TP time period (s)

$R$ radius

Re Reynolds number

Sc Schmidt number

Sh Sherwood number

$T$ temperature

$t$ time

$U$ linear velocity

\section{Greek}

$\sigma \quad$ standard deviation

$\tau$ characteristic time

\section{ACKNOWLEDGMENT}

Acknowledgement is made to the donors of the petroleum research fund administered by ACS for financial support of this research through Grant PRF 13210AC7.

\section{REFERENCES}

1. Hougen, O. H., and Watson, K. M., "Chemical Process Principles," Vol. 3. Wiley, New York, 1943.

2. Weller, S., AIChE J. 2, 59 (1956).

3. Akers, W. W., and White, R. R., Chem. Eng. Prog. 44, 553 (1948).

4. Scheintuch, M., and Schmidtz, R. A., Catal. Rev.-Sci. Eng. 15, 107 (1977).

5. Wagner, C., and Hauffe, K., Z. Electrochem. 45, 409 (1939).

6. Kokes, R. J., Tobin, H., and Emmet, P. H., $J$. Amer. Chem. Soc. 77, 5860 (1955).

7. Tamaru, K., "Advances in Catalysis," Vol. 15, p. 65. Academic Press, New York, 1964.

8. Bennett, C. O., AIChE J. 13, 890 (1967).

9. Kobayashi, H., and Kobayashi, M., Catal. Rev.Sci. Eng. 10(2), 139 (1974).

10. Bennett, C. O., Catal. Rev.-Sci. Eng. 13(2), 121 (1976).

11. Kobayashi, M., Chem. Eng. Sci. 37, 393 (1982).

12. Schadlich, K., Hoffman, U., and Hofman, H., Chem. Eng. Sci. 38, 1375 (1983).

13. Cristoffel, R. G., Catal. Rev.-Sci. Eng. 24, 159 (1982).

14. Bennett, C. O., Cutlip, M. B., and Yang, C. C., Chem. Eng. Sci. 27, 2255 (1972).

15. Finlayson, B. A., ACS Symp. Ser. 65, 300 (1981).

16. Young, C. L., and Finlayson, B. A., AIChE J. 22, 331 (1976).

17. Engel, T., and Ertl, G., J. Chem. Phys., 69(3) (1978).

18. Herz, R. K., and Marin, S. P., J. Catal. 65, 281 (1980).

19. Boersma, M. A. M., Tielen, W. H. M., and Van Der Baan, H. S., ACS Symp. Ser. 65, 72 (1981).

20. Vrentas, J. S., Duda, J. L., and Bargeron, K. G., AIChE J. 2, 837 (1966).

21. Wei, J., ACS Symp. Ser. 148, (1974).

22. Heck, R. H., Wei, J., and Katzer, J. R., ACS Symp. Ser. 133, 34 (1974).

23. Graetz, L., Ann. Phys. U. Chem. 25, 337 (1885).

24. Knudsen, J. G., and Katz, D. L., "Fluid Dynamics and Heat Transfer." McGraw-Hill, New York, 1958.

25. Taylor, G. I., and Aris, R., Proc. R. Soc. London Ser. A 219, 186 (1953).

26. Zhou, X., Barshad, Y., and Gulari, E., Chem. Eng. Sci., in press.

27. Herz, R. K., and Shinouskis, E. J., Presentation at the annual Materials Research Society, Boston, Mass., November 1983. 